\title{
The p53-Mdm2 feedback loop protects against DNA damage by inhibiting p53 activity but is dispensable for p53 stability, development, and longevity
}

\author{
Vinod Pant, ${ }^{1}$ Shunbin Xiong, ${ }^{1}$ James G. Jackson, ${ }^{1}$ Sean M. Post, ${ }^{1}$ Hussein A. Abbas, ${ }^{1}$ \\ Alfonso Quintás-Cardama, ${ }^{1,2}$ Amirali N. Hamir, ${ }^{3}$ and Guillermina Lozano ${ }^{1,4}$ \\ ${ }^{1}$ Department of Genetics, ${ }^{2}$ Department of Leukemia, ${ }^{3}$ Department of Veterinary Medicine and Surgery, The University of Texas \\ M.D. Anderson Cancer Center, Houston, Texas 77030, USA
}

The p53-Mdm2 feedback loop is perceived to be critical for regulating stress-induced p53 activity and levels. However, this has never been tested in vivo. Using a genetically engineered mouse with mutated p53 response elements in the $M d m 2$ P2 promoter, we show that feedback loop-deficient $M d m 2^{P 2 / P 2}$ mice are viable and aphenotypic and age normally. p53 degradation kinetics after DNA damage in radiosensitive tissues remains similar to wild-type controls. Nonetheless, DNA damage response is elevated in $M d m 2^{P 2 / P 2}$ mice. Enhanced p53dependent apoptosis sensitizes hematopoietic stem cells (HSCs), causing drastic myeloablation and lethality. These results suggest that while basal $\mathrm{Mdm} 2$ levels are sufficient to regulate 553 in most tissues under homeostatic conditions, the p53-Mdm 2 feedback loop is critical for regulating p53 activity and sustaining HSC function after DNA damage. Therefore, transient disruption of p53-Mdm2 interaction could be explored as a potential adjuvant/therapeutic strategy for targeting stem cells in hematological malignancies.

[Keywords: hematopoietic stem cells; autoregulatory loop; bone marrow; p53 stability; ionizing radiation] Supplemental material is available for this article.

Received July 23, 2013; revised version accepted July 29, 2013.

The ubiquitously expressed p53 tumor suppressor is maintained normally in an inactive latent form but functions as the "guardian of the genome" in response to DNA damage (Lane 1992). In response to genotoxic stressors, p53 transactivates target genes involved in cell cycle arrest, senescence, or apoptosis pathways to halt progression of insults into heritable aberrations (Vousden and Lu 2002). A range of inhibitors have been identified that regulate p53 activity under normal and stress conditions. Of these, Mdm2 is the major negative regulator of p53. Genetic deletion of $M d m 2$ in vivo results in embryonic lethality that is rescued by concomitant deletion of $p 53$ (Jones et al. 1995; Montes de Oca Luna et al. 1995). The prevailing view suggests that $\mathrm{Mdm} 2$ inhibits p53 by two different mechanisms. Mdm2 binds and masks the transactivation domain of p53 (Momand et al. 1992; Oliner et al. 1993). Furthermore, Mdm2 is also an E3 ubiquitin ligase that promotes p53 degradation through the $26 \mathrm{~S}$ proteasome machinery (Haupt et al. 1997; Honda et al.

${ }^{4}$ Corresponding author

E-mail gglozano@mdanderson.org

Article published online ahead of print. Article and publication date are

online at http://www.genesdev.org/cgi/doi/10.1101/gad.227249.113.
1997; Kubbutat et al. 1997). Interestingly, Mdm2 itself is a transcriptional target of p53, thus establishing a negative feedback loop. After DNA damage, stabilized/activated p53 binds to the P2 promoter of $M d m 2$ and promotes its transcription (Barak et al. 1993; Wu et al. 1993). Mdm2 in turn inhibits p53 via one of the two mechanisms described above.

A wealth of correlative evidence suggests that the p53$\mathrm{Mdm} 2$ autoregulatory loop functions as the principal mode of p53 regulation under normal and DNA damage conditions (Haupt et al. 1997; Saucedo et al. 1998; Mendrysa and Perry 2000; Marine et al. 2006). After DNA damage, p53 levels increase, correlating with enhanced p53 binding at the P2-Mdm2 promoter and a subsequent increase in Mdm2 levels (Barak et al. 1993; Wu et al. 1993; Saucedo et al. 1998). This acute response is soon followed by dampening of p53 back to baseline levels. As increased p53 levels are toxic for cell viability, it is generally believed that $\mathrm{Mdm} 2$ transactivated by $\mathrm{p} 53$ from the $\mathrm{P} 2$ promoter is central for down-modulation of p53. Interestingly, this cytoprotective feature of the p53-Mdm2 feedback loop is considered a major impediment in exploiting the potential of $\mathrm{p} 53$ reactivation as a therapeutic strategy in tumors with wild-type p53. However, in the absence of 
an in vivo model, these hypotheses could not be directly evaluated.

To investigate the biological significance of the dual $M d m 2$ promoters and the p53-Mdm2 autoregulatory loop in vivo, we generated a knock-in mouse model with a defective p53-Mdm2 autoregulatory loop and analyzed the effects of the feedback deficiency during development and under normal and DNA damage conditions.

\section{Results}

Generation of $M d m 2^{P 2 / P 2}$ mice

To examine the in vivo significance of the p53-Mdm2 autoregulatory loop, we generated a knock-in mouse by mutating the critical $\mathrm{C}$ and $\mathrm{G}$ nucleotides in the two p53 response elements of the P2-Mdm2 promoter (Fig. 1A,B). This in vivo approach allowed us to specifically abrogate p53-mediated up-regulation of Mdm2 while maintaining the normal stoichiometry and functionality of other p53 pathway components. The abrogation of $\mathrm{P} 2$ promoter function was verified by in vitro luciferase reporter assay prior to cloning of the mutant promoter fragment into the targeting vector (data not shown). The targeting construct (Fig. 1A) with a mutant Mdm2 P2 promoter was electroporated into TC1 mouse embryonic stem (ES) cells. Correctly targeted ES clones were identified by Southern blotting using $5^{\prime}$ and $3^{\prime}$ external probes (Fig. 1A) and injected into C57BL/6 blastocysts to generate $M d m 2^{+/ P 2}$ chimeras. Male chimeras $(>80 \%)$ were backcrossed to C57BL/6 mice to secure germline transmission of the mutant allele. The Neomycin selection cassette was subsequently deleted by crossing with $Z p 3$-Cre deleter mice (Lewandoski et al. 1997). A PCR-based genotyping strategy on genomic DNA isolated from tail biopsies was used to follow the transmission of the mutant allele. Mice were backcrossed for a total of four generations to $>90 \%$ C57BL/6 background for this study.

$M d m 2^{P 2 / P 2}$ mice are born in a normal Mendelian ratio

We intercrossed heterozygous $M d m 2^{+/ P 2}$ mice to generate $M d m 2^{P 2 / P 2}$ homozygous mice. Surprisingly, $M d m 2^{P 2 / P 2}$ mice were born at an appropriate Mendelian ratio with no phenotypic aberrations (Supplemental Fig. 1). We sequenced the genomic DNA from an $M d m 2^{P 2 / P 2}$ homozygous mouse and confirmed the mutations in the germline (Fig. 1B). We next generated $M d m 2^{P 2 /-}$ mice with further reduced Mdm2 levels. Again, both $M d m 2^{P 2 / P 2}$ and $M d m 2^{P 2 /-}$ mice survived to adulthood lacking any distinctive phenotype. These results demonstrate that reduction in the P2-Mdm2 (Mdm2 expressed from the P2 promoter) level does not lead to lethal activation of p53. Thus, the autoregulatory loop is dispensable for normal development.

\section{Mutations abrogate p53 binding at the P2-Mdm2 promoter}

We next tested the specificity of P2-Mdm2 promoter mutations by performing in vivo chromatin immunoprecipitation (ChIP) assays. We isolated spleens from $M d m 2^{P 2 / P 2}$ and
$\mathrm{Mdm} 2^{+/+}$mice after irradiation. Unirradiated $\mathrm{Mdm} 2^{+/+}$ and $M d m 2^{P 2 / P 2}$ mouse spleens were obtained as controls at the same time. In vivo ChIP with a p53 antibody followed by real-time PCR analyses confirmed abrogation of p53 binding at the mutant Mdm2 promoter (Fig. 1C), while p53 still bound to the promoters of canonical targets p21 and Puma. Notably, p53 binding to the $p 21$ promoter was significantly enhanced in irradiated $M d m 2^{P 2 / P 2}$ mouse spleens compared with $M d m 2^{+/+}$spleens for unknown reasons.

Degradation profile of p53 after ionizing radiation (IR) is not altered in $M d m 2^{P 2 / P 2}$ mice

According to current dogma, degradation of the accumulated p53 after DNA damage is attributed to its ability to transactivate $M d m 2$, which encodes the major E3 ubiquitin ligase for p53 (Wu et al. 1993; Barak et al. 1994; Zauberman et al. 1995; Haupt et al. 1997; Honda et al. 1997; Kubbutat et al. 1997). Therefore, we first investigated the role of Mdm2 in p53 degradation after IR in feedback-deficient $M d m 2^{P 2 / P 2}$ mice. We isolated spleens from irradiated $M d m 2^{+/+}$and $M d m 2^{P 2 / P 2}$ mice at different time points. Immunoblotting of protein lysate revealed the anticipated post-IR induction of p53 in both genotypes (Fig. 2A). A slight increase in p53 induction at the 4-h post-IR time point in $M d m 2^{P 2 / P 2}$ spleens in comparison with $M d m 2^{+/+}$ spleens was noticeable (Fig. 2A). Nonetheless, the pattern of p53 degradation in $M d m 2^{P 2 / P 2}$ spleens remained similar to $M d \mathrm{~m}^{+/+}$spleens. In both genotypes, p53 was stabilized $2 \mathrm{~h}$ after IR, peaked by $4 \mathrm{~h}$, and subsequently returned to baseline levels by $8 \mathrm{~h}$. As expected, Mdm2 induction was visible only in $M d m 2^{+/+}$spleens in response to IR. To evaluate the role of the p53-Mdm2 feedback loop in p53 stability in other tissues, we further examined post-IR induction and degradation profiles of p53 in the skin, thymus, lungs, and kidneys of $M d m 2^{+/+}$and $M d m 2^{P 2 / P 2}$ mice (Fig. 2B). Again, a similar pattern of p53 induction and degradation was observed in the tissues of mice from either genotype (Fig. 2B). Of note, a slight delay in p53 decay was observed only in the $M d m 2^{P 2 / P 2}$ mouse skin. As expected, no induction of p53 was observed in the liver.

We also examined the impact of further reduced Mdm2 levels on p53 levels by analyzing p53 degradation in spleens from irradiated $M d m 2^{P 2 /-}$ mice. p53 induction was comparatively higher in $M d m 2^{P 2 /-}$ mouse spleens after IR due to minimal $\mathrm{Mdm} 2$ expression from a single allele containing only the $\mathrm{P} 1$ promoter (Fig. 2C). Nonetheless, the degradation profiles of $\mathrm{p} 53$ in $M d m 2^{P 2 /-}$ spleens were similar to that of $M d m 2^{P 2 / P 2}$ spleens (Fig. 2C). A dramatic decrease of p53 levels was observed $6 \mathrm{~h}$ after IR in both genotypes. However, p53 levels were not quite back to baseline at the 8 -h time point in $M d m 2^{P 2 /-}$ spleens. Of note, while loss of Mdm2 stabilizes p53 in vivo (Francoz et al. 2006; Ringshausen et al. 2006; Xiong et al. 2006; Terzian et al. 2008), we did not observe any overt p53 stabilization in $M d m 2^{P 2 / P 2}$ or $M d m 2^{P 2 /-}$ tissues in the absence of DNA damage (Fig. 2), indicating that basal levels of $\mathrm{Mdm} 2$ expressed from the $\mathrm{P} 1$ promoter are 


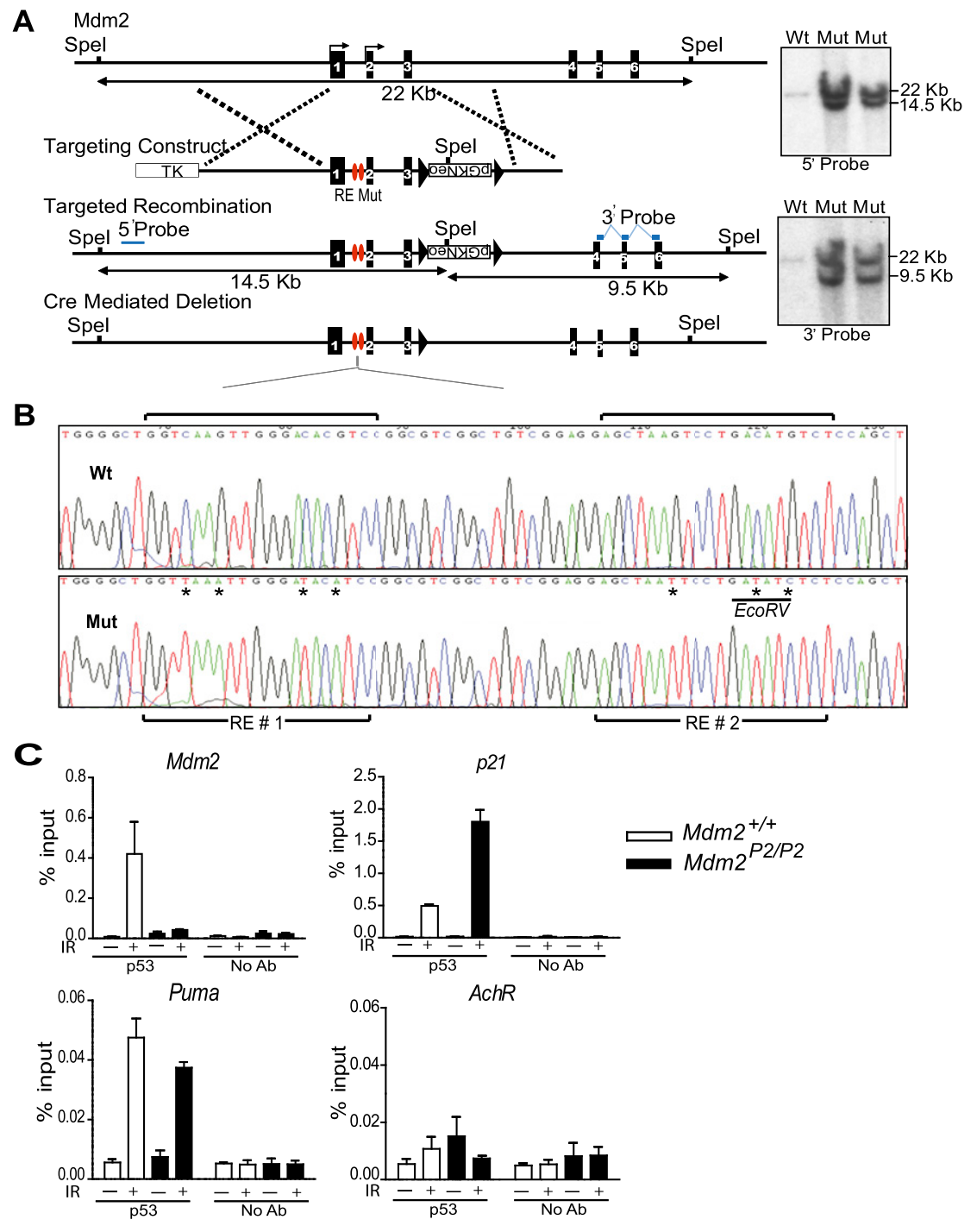

Figure 1. Generation of $M d m 2^{P 2 / P 2}$ knockin allele. $(A)$ Schematic representation of the targeting vector carrying mutations of the p53 response elements in the $\mathrm{P} 2$ promoter of the $M d m 2$ gene. Filled black boxes represent numbered exons, while the red ovals depict the mutations. The targeting construct contained $\mathrm{Hsv}$-Tk and loxP-flanked (filled triangles) PGK-neo cassettes for negative and positive selection, respectively. Also shown are the $5^{\prime}$ and $3^{\prime}$ external probes used to genotype the ES cell lines. The side panel shows Southern blot analysis of the SpeIdigested genomic DNA from ES cell clones. (B) Partial P2 promoter sequence from the wild-type and mutant $M d m 2$ alleles. Asterisks denote the mutated nucleotides. $(C)$ ChIP assays with p53 antibody to examine p53 binding at the $M d m 2$, p21, and Puma promoters $4 \mathrm{~h}$ after 6 Gy IR. $n=3$, \pm SEM. Acetylcholine receptor (AchR) promoter was used as negative control for the assay. sufficient to maintain normal p53 levels. The viability of these mice further supports this conclusion.

p53 degradation profile after ultraviolet radiation (UV) damage is not altered in $M d m 2^{P 2 / P 2}$ mice

We also tested whether another type of DNA damage could induce the feedback loop and alter p53 degradation. We used UV, which creates pyrimidine dimers to activate p53 (Saucedo et al. 1998). Mouse embryonic fibroblasts (MEFs) from $M d m 2^{+/+}$and $M d m 2^{P 2 / P 2}$ mice were exposed to $50 \mathrm{~J} / \mathrm{m}^{2} \mathrm{UV}$ and harvested at different time points. Protein lysates were analyzed by immunoblotting (Fig. 2D). Notably, p53 was stabilized in both sets after UV exposure, while an enhanced Mdm2 induction was restricted to $M d m 2^{+/+}$lysates. Moreover, the overall pattern of p53 induction and down-regulation remained similar in both MEF cell lines (Fig. 2D). These data emphasize the importance of basal Mdm2 levels in regulating p53 levels in response to DNA damage.
Tissues from $M d m 2^{P 2 / P 2}$ mice show higher levels of p53 activity after DNA damage

In vivo, loss of $M d m 2$ alone results in spontaneous p53 activation (Jones et al. 1995; Montes de Oca Luna et al. 1995; Mendrysa et al. 2003; Francoz et al. 2006; Ringshausen et al. 2006; Xiong et al. 2006). Therefore, we next examined whether p53 activity was altered in $M d m 2^{P 2 / P 2}$ mice. We isolated total RNA from unirradiated and irradiated $M d m 2^{+/+}$and $M d m 2^{P 2 / P 2}$ thymi and performed RT-qPCR analyses for p53 targets. A significant increase $(P<0.01)$ in p21 and Puma transcript levels was observed in $M d m 2^{P 2 / P 2}$ mice compared with $M d m 2^{+/+}$mice (Fig. 3A). Analogous analyses of p53 targets in RNA from spleens also showed modest increase in transcript levels of p53 target genes CyclinG1, Noxa, Puma, p21, and Bax in $M d m 2^{P 2 / P 2}$ mice (Fig. 3B). Notably, p21 levels were significantly higher in $M d m 2^{P 2 / P 2}$ mice, in agreement with the ChIP data (Fig. 1C) and Western blot analysis (Fig. 2A). No differences in basal transcript levels of these p53 target genes were observed between unirradiated $M d m 2^{+/+}$ 
Pant et al.

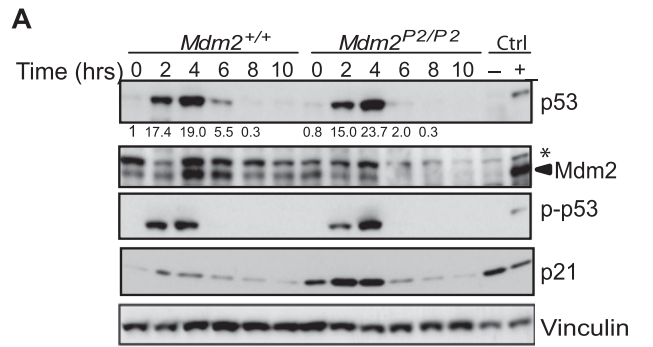

B
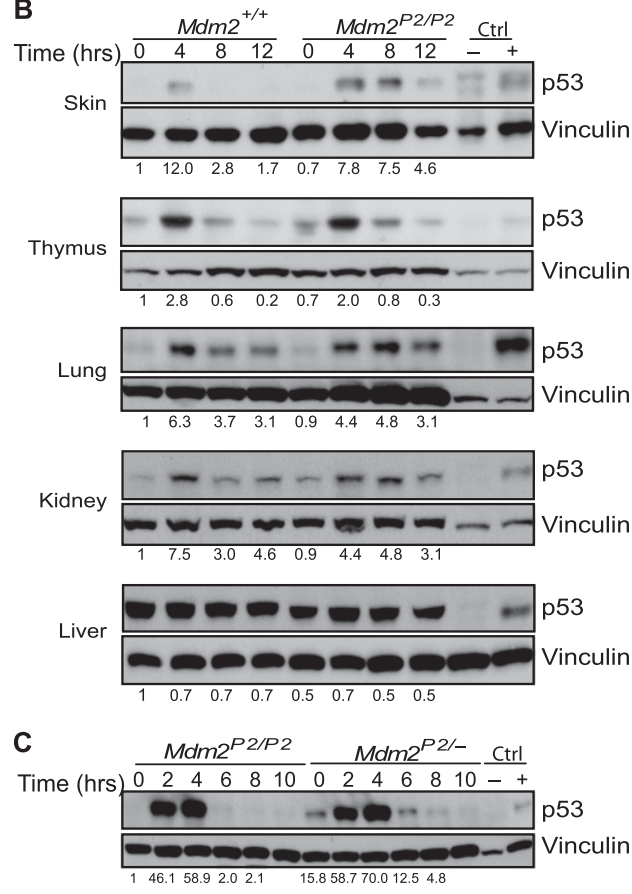

D

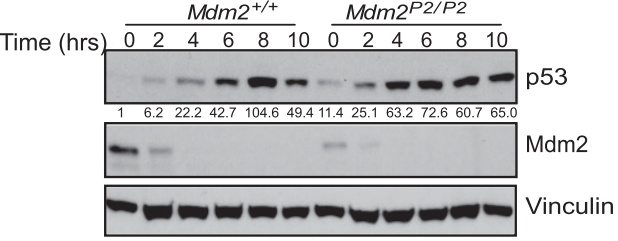

Figure 2. The $\mathrm{Mdm} 2$ generated from the $\mathrm{P} 2$ promoter is not involved in DNA damage-induced p53 degradation. (A) Western blot analysis for post-IR p53 levels in $6 \mathrm{~Gy}$ irradiated $\mathrm{Mdm} 2^{+/+}$ and $M d m 2^{P 2 / P 2}$ mouse spleens at different time points. (-) Negative controls for p53/Mdm2 expression; $(+)$ positive controls for p53/Mdm2 expression; (arrowhead) Mdm2 band; (*) nonspecific band. The bottom panels show dynamics of Mdm2, p21, and S18-p53 induction. (B) Western blot analysis for p53 levels in $6 \mathrm{~Gy}$ irradiated $M d m 2^{+/+}$and $M d m 2^{P 2 / P 2}$ mouse skin, lung, thymus, kidney, and liver tissues. $(C)$ Western blot analysis for p53 kinetics in $M d m 2^{P 2 /-}$ and $M d m 2^{P 2 / P 2}$ mouse spleens. $(D)$ Time course for p53 induction and degradation in MEF cells exposed to $50 \mathrm{~J} / \mathrm{m}^{2} \mathrm{UV}$. Vinculin was used as loading control in these experiments. Blots are representative of three independent biological replicates. Numbers at the bottom denote p53 fold induction normalized to vinculin controls and relative to untreated $\mathrm{Mdm} 2^{+/+}$controls.

and $M d m 2^{P 2 / P 2}$ tissues (Fig. 3A,B). Additionally, no increase in $M d m 2$ transcripts was observed in either tissue from irradiated $M d m 2^{P 2 / P 2}$ mice, in conformity with the
ChIP data (Fig. 3A,B). These results corroborate that the autoregulatory loop is engaged primarily under stress conditions (Mendrysa and Perry 2000) and also imply that in the absence of exogenous stress stimuli, basal levels of Mdm2 from the P1 promoter are sufficient for regulating p53 activity.

\section{Enhanced $p 53$ functions in $M d m 2^{P 2 / P 2}$ mice}

p53 functions to maintain genomic integrity by inducing apoptosis, cell cycle arrest, or senescence in damaged cells (Vousden and Lu 2002). To examine the acute impact of DNA damage on p53 function, we performed AnnexinV FITC flow cytometry analyses on thymocytes isolated from irradiated $\mathrm{Mdm}^{+/+}$and $M d m 2^{P 2 / P 2}$ mice. An increase in apoptotic response was observed in $M d m 2^{P 2 / P 2}$ thymocytes, although this was not statistically significant $(P=0.15)$ (Fig. 3C; Supplemental Fig. 2). To further examine the effect on cell cycle, we next used MEFs that preferentially undergo p53-dependent cell cycle arrest after DNA damage. We irradiated $\mathrm{Mdm}^{+/+}$and $M d m 2^{P 2 / P 2}$ MEFs and, after confirming p53 up-regulation (Supplemental Figure 3 ), analyzed them by flow cytometry. We observed a statistically significant decrease $(P<0.001)$ in the S-phase population of $M d m 2^{P 2 / P 2}$ MEFs compared with $M d m 2^{+/+}$in response to IR (Fig. 3D,E). Irradiated $M d m 2^{P 2 / P 2}$ MEFs also had significantly higher $(P<0.05)$ p21 mRNA levels as compared with $M d m 2^{+/+}$MEFs (Fig. $3 \mathrm{~F})$. Furthermore, as cell culture is itself a stressed system, we analyzed MEF growth using 3-(4,5-dimethylthiazol2-yl)-2,5-diphenyltetrazolium bromide (MTT) assay (Fig. 3G). Again, in confirmation with high p53 activity, the cell growth rate of $M d m 2^{P 2 / P 2}$ MEFs was lower than $M d \mathrm{~m}^{+/+}$MEFs. These data suggest that a defective autoregulatory loop augments p53-dependent activities after stress.

\section{$M d m 2^{P 2 / P 2}$ mice are extremely radiosensitive}

Changes in Mdm2 levels impact radiation response and survival in mice (Mendrysa et al. 2003, 2006; Ringshausen et al. 2006; Terzian et al. 2007). To specifically investigate the importance of the p53-Mdm2 feedback loop long term, we irradiated mice with a sublethal dose of 6 Gy IR. While $100 \%$ of irradiated $M d m 2^{+/+}$mice survived $50 \mathrm{~d}$ (the duration of the experiment) with no significant pathology, $80 \%$ of irradiated $M d m 2^{P 2 / P 2}$ mutant mice died within $25 \mathrm{~d}$ (Fig. 4A). This is similar to the post-IR lethality of $M d m 2^{+/-}$and $M d m 2$ hypomorphic mice (Mendrysa et al. 2003; Terzian et al. 2007). However, in contrast to these published studies, $M d m 2^{P 2 / P 2}$ mice have normal levels of basal $M d m 2$ from P1 promoter and only lack expression of p53-induced P2-Mdm2.

We next assessed the impact of gene dosage of $M d m 2$ and its homolog, $M d m 4$, in determining radiation sensitivity of $M d m 2^{P 2 / P 2}$ mice. We compared the survival of $M d m 2^{P 2 / P 2}$, $M d m 2^{P 2 /-}$, and $M d m 2^{P 2 / P 2} M d m 4^{\Delta 2 /+}$ mice with $M d m 2^{+/-}$ and $M d m 4^{\Delta 2 /+}$ mice after 6 Gy IR (Fig. 4B). As anticipated, the reduction in $\mathrm{Mdm} 2$ and Mdm4 levels further enhanced the radiosensitivity of $M d m 2^{P 2 / P 2}$ mice. We also 

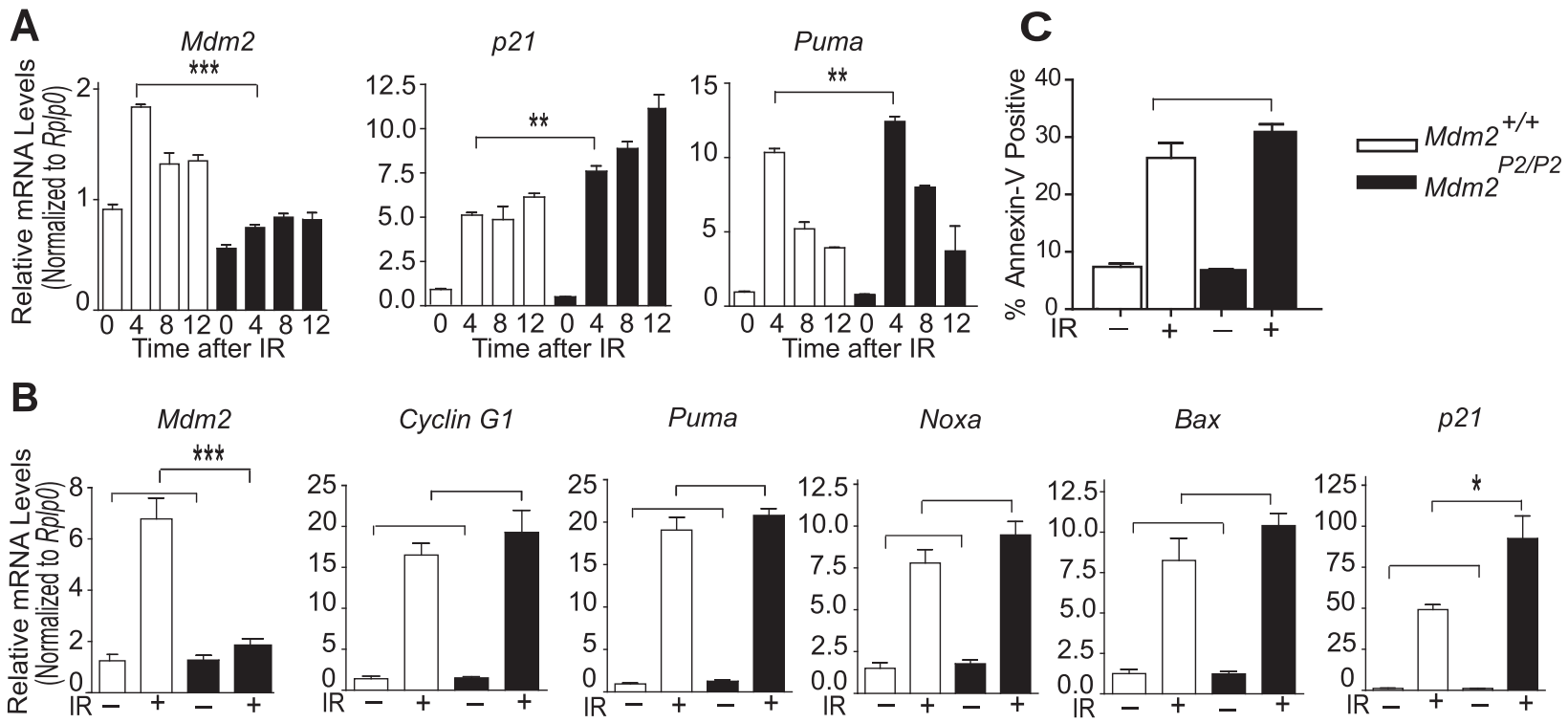

Cyclin $\mathrm{G1}$
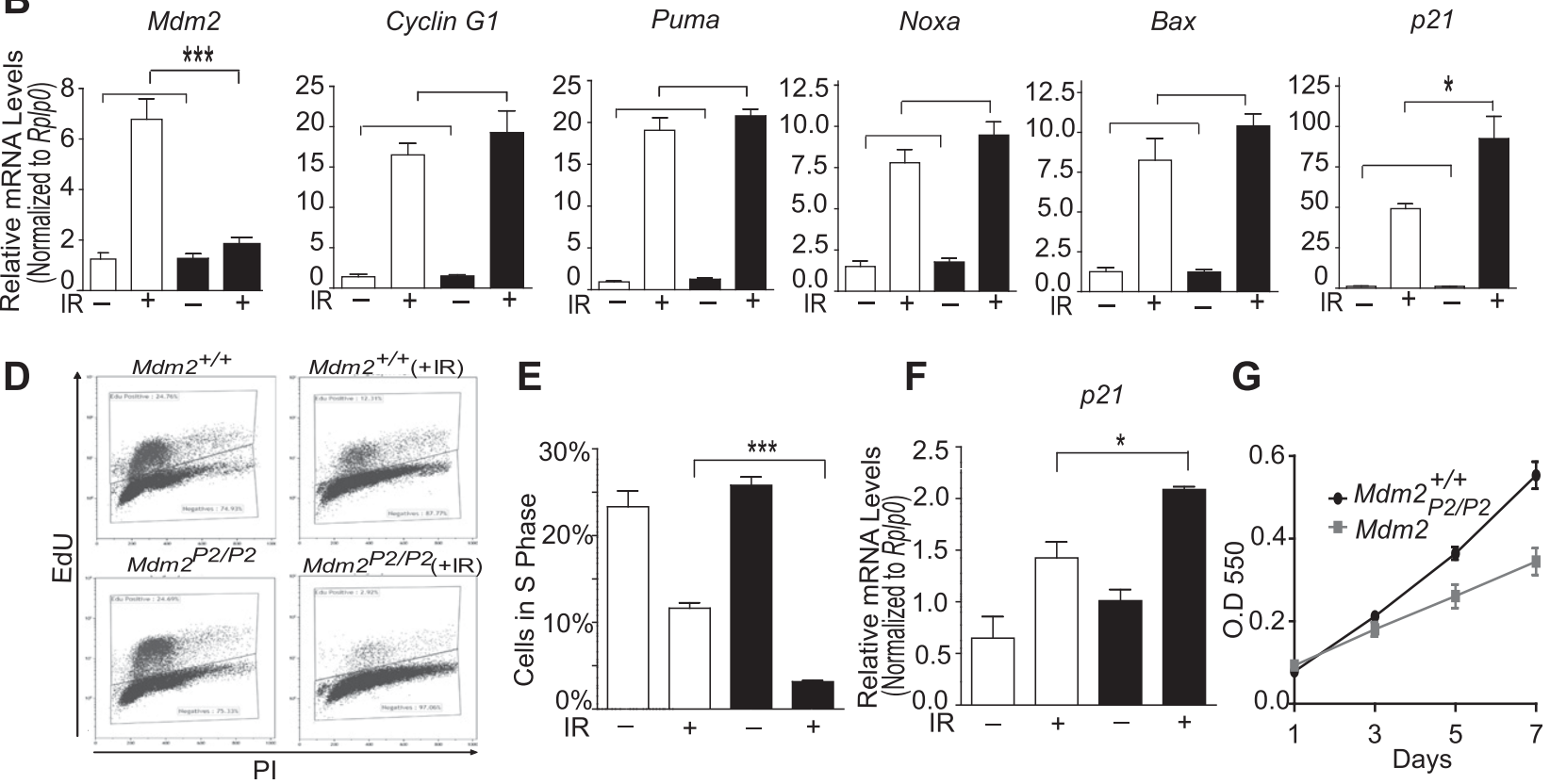

Figure 3. Enhanced p53 activity after DNA damage in specific tissues. $(A)$ RT-qPCR analysis for p53 targets in thymi from $M d m 2^{+/+}$ and $M d m 2^{P 2 / P 2}$ mice $\left(n=3, \pm\right.$ SEM). (B) RT-qPCR analysis of p53 transactivation function in spleens from $M d m 2^{+/+}$and $M d m 2^{P 2 / P 2}$ mice $\left(n=6, \pm\right.$ SEM) $4 \mathrm{~h}$ after 6 Gy IR. $(C)$ Quantification of flow cytometry data for apoptosis in thymocytes from $M d m 2^{+/+}$and $M d m 2^{P 2 / P 2}$ mice $(n=5-6, \pm$ SEM) 4 h after 6 Gy IR. (D) Representative forward/side scatter profiles of irradiated and unirradiated MEFs from $M d m 2^{+/+}$and $M d m 2^{P 2 / P 2}$ mice. (E) Quantification of cells in S phase from $D$. (F) RT-qPCR for p53 target gene $p 21$ in MEFs. Three separate MEF lines per genotype were used for analyses. In all RT-qPCR experiments, mRNA expression was normalized to RplpO levels, and wild-type -IR was set to $1 .(G)$ Cell growth analyses of $M d m 2^{+/+}$and $M d m 2^{P 2 / P 2} \mathrm{MEFs}$. $P$-values were calculated by unpaired Student's $t$-test, and a value $<0.05$ was considered significant. $\left({ }^{\star}\right) P<0.05 ;\left(^{\star \star}\right) P<0.01 ;\left(^{\star \star \star}\right) P<0.001$.

explored potential gender differences in determining radiosensitivity in $M d m 2^{P 2 / P 2}$ mice. However, no such difference was evident (Supplemental Fig. 4). These data suggest that the feedback loop is important for Mdm2mediated inhibition of p53 activity and survival after DNA damage.

Irradiated $M d \mathrm{~m} 2^{P 2 / P 2}$ mice die due to p53-dependent bone marrow (BM) ablation

To identify the particular tissue type severely affected by radiation in the absence of the feedback loop and instigating the demise of irradiated $M d m 2^{P 2 / P 2}$ mice, we next performed a comparative histopathological examination of all major radiosensitive tissues from $M d m 2^{P 2 / P 2}$ and $M d \mathrm{~m}^{+/+}$mice. We observed mild to moderate hypoplasia of the spleen and thymus with atrophy of both the splenic white pulp and the thymic cortex (Supplemental Fig. 5). Areas of mild atrophy were also observed in the mucosa of the stomach, duodenum, and small/large intestine. A noted decline in cellularity was observed in BM sections from both genotypes, culminating in profound aplasia in $M d m 2^{P 2 / P 2}$ mice by day 12 , while $M d m 2^{+/+}$ mice recovered (Fig. 4C). Peripheral blood cell counts at this time point revealed severe thrombocytopenia and neutropenia as well as moderate anemia in $\mathrm{Mdm} 2^{P 2 / P 2}$ mice (Supplemental Fig. 6A). Additionally, BM differential analysis showed significant depletion of less differentiated elements of the white cell lineage in $M d m 2^{P 2 / P 2}$ mice (Supplemental Fig. 6B). Immunohistochemical analyses of BM sections with phospho-histone $\mathrm{H} 3$ and Ki-67 antibodies also revealed the absence of mitosis/proliferation in $M d m 2^{P 2 / P 2}$ compared with $M d m 2^{+/+}$irradiated mice (Supplemental Fig. 7A,B).

Overall, these results suggested that the death of $M d m 2^{P 2 / P 2}$ mice was likely a consequence of BM failure, a tissue overtly sensitive to radiation-induced p53 ac- 
Pant et al.

A

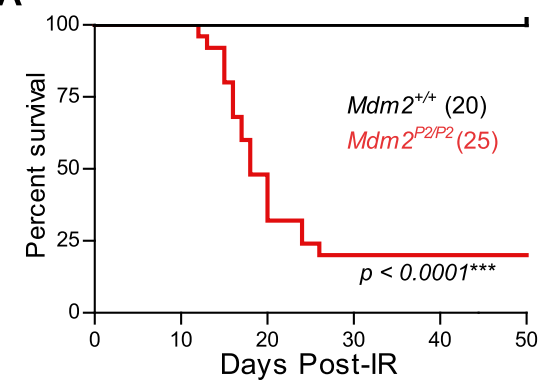

B

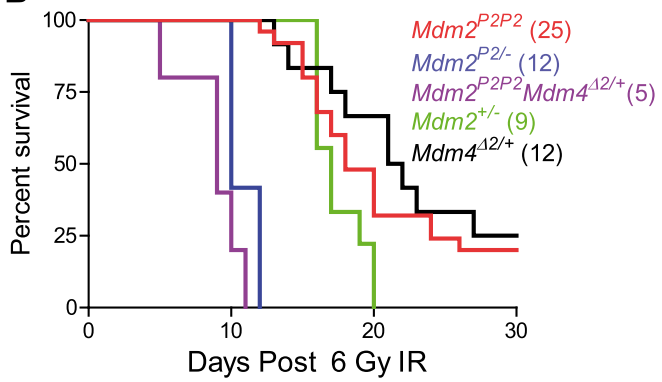

C

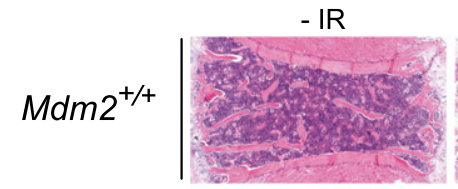

1 day

3 days

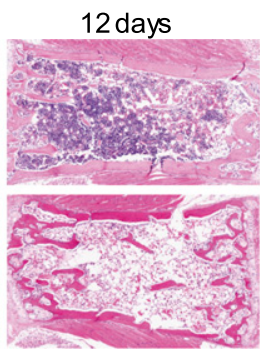

D

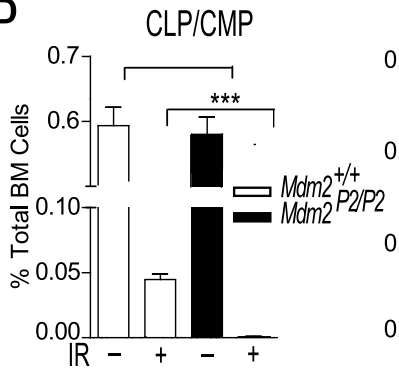

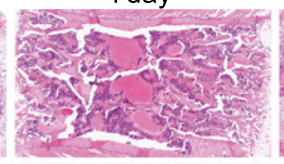
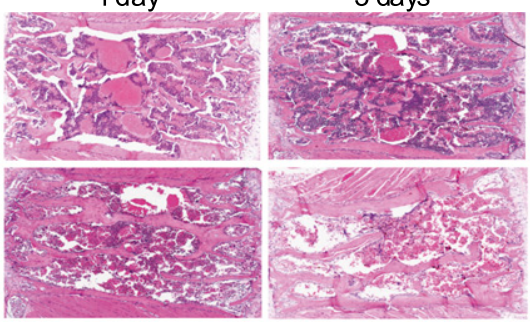

HSC (LSK)

$\mathbf{E}$

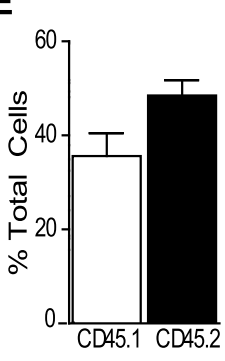

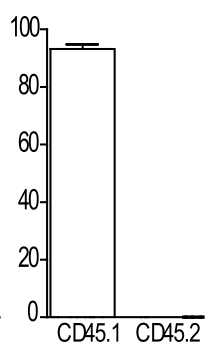

F

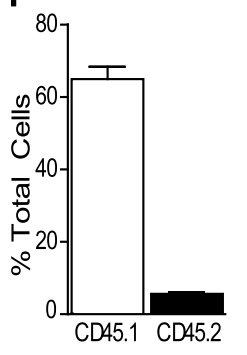

Figure 4. Absence of feedback loop results in extreme radiosensitivity in $M d m 2^{P 2 / P 2}$ mice. $(A)$ Kaplan-Meier survival curves for 6 Gy irradiated $M d m 2^{+/+}$and $M d m 2^{P 2 / P 2}$ mice. (B) Kaplan-Meier survival curves for $6 \mathrm{~Gy}$ irradiated $M d m 2^{P 2 / P 2}, M d m 2^{P 2 /-}, M d m 2^{P 2 / P 2} M d m 4^{\Delta 2 /+}$, $M d m 2^{+/-}$, and $M d m 4^{\Delta 2 /+}$ mice. $(C)$ Hematoxylin and eosin-stained BM sections of 6 Gy irradiated $M d m 2^{+/+}$and $M d m 2^{P 2 / P 2}$ mice at different time points (10× magnification). (D) Quantification of surviving CLPs/CMPs and HSCs (LSK) from 6 Gy irradiated and unirradiated $M d m 2^{+/+}$and $M d m 2^{P 2 / P 2}$ mouse BM 8 h after IR. $n=3, \pm S E M ; P$-value was calculated by unpaired Student's $t$-test, $\left({ }^{\star \star \star}\right) P<0.001 .(E)$ Peripheral blood leukocyte marker analysis of lethally irradiated recipient wild-type CD45.1 mice after competitive BM transplantation with 1:1 mix of unirradiated wild-type (CD45.1) and $M d m 2^{P 2 / P 2}$ cells (CD45.2) (left graph) or 4:1 mix of irradiated Mdm2 $2^{P 2 / P 2}$ (CD45.2) and unirradiated wild-type (CD45.1) BM cells (right graph) 16 wk after transplantation. $n=5, \pm$ SEM. (F) Peripheral blood leukocyte marker analysis of lethally irradiated recipient $M d m 2^{P 2 / P 2}$ mice $16 \mathrm{wk}$ after BM transplantation with wild-type CD45.1 cells. $n=4, \pm$ SEM.

tivity (Komarova et al. 2004; Ringshausen et al. 2006; Terzian et al. 2007; Wang et al. 2011). To further confirm that the BM aplasia in $M d m 2^{P 2 / P 2}$ mice was indeed a p53dependent phenotype, we generated $M d m 2^{P 2 / P 2} p 53^{+/-}$ and $M d m 2^{P 2 / P 2} p 53^{-/-}$mice and exposed them to $6 \mathrm{~Gy}$ IR. Both genotypes completely averted BM failure and survived the radiation dosage (Supplemental Fig. $8 \mathrm{~A}, \mathrm{~B})$.

\section{Irradiated $M d m 2^{P 2 / P 2}$ mice exhibit hematopoietic} stem cell (HSC) defects

Next, to characterize the particular cell types sensitized by loss of the p53-Mdm2 feedback loop in irradiated $M d m 2^{P 2 / P 2}$ mice, we performed flow cytometry analyses of BM constituent cells from $M d m 2^{P 2 / P 2}$ and $M d m 2^{+/+}$ mice. Flow cytometry analysis revealed similar cell numbers in unirradiated mice of both genotypes but an acute and statistically significant $(P<0.001)$ depletion of com- mon lymphoid progenitor cells (CLPs)/common myeloid

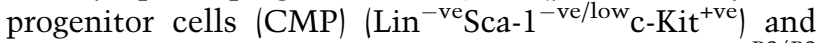
HSCs $\left(\mathrm{Lin}^{-\mathrm{ve}} \mathrm{Sca}-1^{+\mathrm{ve}} \mathrm{c}-\mathrm{Kit}^{+\mathrm{ve}}\right)$ in irradiated $\mathrm{Mdm} 2^{P 2 / P 2}$ mice (Fig. 4D).

p53 is important for maintaining HSC quiescence (Liu et al. 2009). To further confirm and characterize the role of the p53-Mdm2 feedback loop in HSC function, we examined the long-term engraftment potential of $M d m 2^{P 2 / P 2}$ HSCs by competitive and noncompetitive BM transplantation. We mixed BM cells from unirradiated $M d m 2^{P 2 / P 2}$ (expressing the CD45.2 leukocyte marker) and wild-type (expressing the CD45.1 leukocyte marker) mice in a 1:1 ratio and transplanted them into lethally irradiated wildtype recipient mice. Peripheral blood analysis after $16 \mathrm{wk}$ confirmed normal engraftment and contribution to hematopoietic lineage by the $M d m 2^{P 2 / P 2}$ HSCs (Fig. 4E). However, in a similar transplantation experiment in parallel, a mix of irradiated $M d m 2^{P 2 / P 2} \mathrm{BM}$ cells with unirradiated wild-type cells in a 4:1 ratio failed to engraft 
and contribute to hematopoiesis. This suggested that $M d m 2^{P 2 / P 2}$ HSCs are functionally normal in the absence of DNA damage. Furthermore, we also rescued the lethality of irradiated $M d m 2^{P 2 / P 2}$ mice by transplanting BM cells from unirradiated wild-type mice (Fig. 4F). Additionally, lethally irradiated wild-type mice transplanted with $\mathrm{Mdm} 2^{P 2 / P 2} \mathrm{BM}$ cells in a noncompetitive assay acquired radiosensitivity (Supplemental Fig. 9). These results confirmed that the p53-dependent post-IR sensitivity in $M d m 2^{P 2 / P 2}$ mice was associated with stem cells per se and not the niche. Thus, the p53-Mdm2 feedback loop is critical for attenuating p53 response in the HSCs after genotoxic insults.

\section{p53-mediated apoptosis causes HSC depletion} in $\mathrm{Mdm} 2^{P 2 / P 2}$ mice

The p53 damage response predominantly initiates either cell cycle arrest or apoptosis. To identify the preferential p53 downstream pathway involved in the post-IR attrition of BM cells in feedback loop-deficient $M d m 2^{P 2 / P 2}$ mice, we first examined expression of two p53 transcriptional targets: $p 21$, which encodes a cell cycle inhibitor, and Puma, a proapoptotic gene in BM cells of $M d m 2^{P 2 / P 2}$ mice. These genes have been previously implicated in radiosensitivity and HSC regulation (Cheng et al. 2000; van Os et al. 2007; Abbas et al. 2010; Shao et al. 2010; Yu et al. 2010). While the baseline levels were similar between $M d m 2^{+/+}$and $M d m 2^{P 2 / P 2}$ mice, we observed a significant and prolonged induction of these genes in irradiated $M d m 2^{P 2 / P 2} \mathrm{BM}$ cells compared with irradiated $M d m 2^{+/+}$BM cells (Fig. 5A). As expected, $M d m 2$ mRNA levels were only induced in irradiated $M d \mathrm{~m}^{+/+} \mathrm{BM}$ cells (Supplemental Fig. 10).

Next, we crossed $M d m 2^{P 2 / P 2}$ mice to $p 53^{515 C / 515 C}$ mice and generated $M d m 2^{P 2 / P 2} p 53^{515 C / 515 C}$ mice. Previously, our laboratory had shown that $p 53^{515 C / 515 C}$ mice express a mutant form of $\mathrm{p} 53$ (p53R172P) that activates only cell cycle arrest (partially) but not apoptotic programs (Liu et al. 2004). Interestingly, $M d m 2^{P 2 / P 2} p 53^{515 C / 515 C}$ mice survived exposure to 6 Gy IR (see Supplemental Fig. 8B). This suggested a predominance of the p53 apoptotic pathway in radiosensitization of $M d m 2^{P 2 / P 2} \mathrm{BM}$ cells.

Next, to directly evaluate the role of apoptosis in postIR BM attrition, we performed Annexin-V FITC flow cytometry analysis on BM cells from irradiated $M d m 2^{+/+}$ and $M d m 2^{P 2 / P 2}$ mice (Supplemental Fig. 11). We could not detect a significant difference in apoptosis between the two genotypes using various doses of IR analyzed at different time points. It is possible that the rate of apoptosis essentially remains the same between the two genotypes but is prolonged in the case of $M d m 2^{P 2 / P 2}$ mice, causing increased loss of BM cellularity. A sustained induction of Puma (Fig. 5A) also supports this notion.

Finally, to segregate the in vivo role of apoptosis and cell cycle arrest pathways in radiation-induced BM aplasia, we crossed $M d m 2^{P 2 / P 2}$ mice with $p 21$-null or Puma-null mice. Notably, Puma deficiency but not lack of $p 21$ completely rescued the radiosensitivity (Fig. 5B,C). Furthermore, Puma heterozygosity also rescued the phe- notype (Fig. 5C), thereby confirming that in the absence of the feedback loop, p53-mediated apoptosis is the principal pathway involved in HSC depletion.

\section{$\mathrm{Mdm} 2^{P 2 / P 2}$ mice have a normal life span}

Increase in p53 activity is also linked with increased genomic aberrations, stem cell depletion, and aging phenotypes (Tyner et al. 2002; Liu et al. 2010). To rule out the possibility that reduced levels of stress-induced $\mathrm{Mdm} 2$ in the feedback-defective $M d m 2^{P 2 / P 2}$ mouse could modulate stem cell function throughout life and impact survival, we monitored a cohort of $M d m 2^{P 2 / P 2}, M d m 2^{P 2 /-}$, and $M d m 2^{+/+}$mice long term. No difference in survival was evident between the genotypes (Fig. 6A). Furthermore, the $M d m 2^{P 2 / P 2}$ and $M d m 2^{P 2 /-}$ mice reproduced and aged normally under standard nonstress laboratory conditions. This further confirms that the p53-Mdm2 feedback loop is dispensable for development and that its mere absence is not detrimental for normal functions. Moreover, basal $\mathrm{Mdm} 2$ levels from a single promoter (P1) are sufficient to regulate p53 and sustain life.

Finally, we examined whether exposure to a minor genotoxic insult capable of inducing p53 and initiating the feedback loop could alter the survival profile of these mice (Christophorou et al. 2006; Post et al. 2010; Gannon et al. 2012). To that end, we exposed $M d m 2^{P 2 / P 2}$ and $M d \mathrm{~m}^{+/+}$mice to $3 \mathrm{~Gy}$ IR and monitored them for survival (Fig. 6B). No difference in survival was evident in either group. In addition, the post-IR survival of $M d m 2^{P 2 / P 2}$ and $M d \mathrm{~m}^{+/+}$mice (Fig. 6B) was quite similar to the unirradiated mouse cohort (Fig. 6A). This suggests that a minor transient increase in p53 activity even in the absence of the p53-Mdm2 feedback loop is well tolerated and does not alter long-term stem cell functionality and overall survival.

\section{Discussion}

In the present study, using a mouse model with mutations at the $p 53$-binding site in the $M d m 2 \mathrm{P} 2$ promoter, we provide the first in vivo characterization of the p53Mdm2 feedback loop. In contrast to the prevailing paradigm, our results show that the p53-Mdm2 feedback loop is not essential for development, homeostasis, and longevity. Thus, constitutive Mdm2 levels expressed from the P1 promoter are sufficient for maintaining normal p53 protein levels. A second surprise is that after DNA damage, even in the absence of induced Mdm2 expression, the p53 degradation profile does not change. p53 levels appear at $\sim 2 \mathrm{~h}$ after radiation, peak at $4 \mathrm{~h}$, and are barely detectable by $8 \mathrm{~h}$ in the radiosensitive spleen in normal mice and mice that lack the feedback loop. A similar pattern of p53 degradation is also evidenced in other tissues, such as the skin, thymus, lungs, and kidneys of these mice.

Still, p53 degradation is impeded in a Mdm2 mutant/ null background (Ringshausen et al. 2006; Itahana et al. 2007). This suggests that additional factors may be involved in signaling p53 degradation. One possibility is 
Pant et al.

A

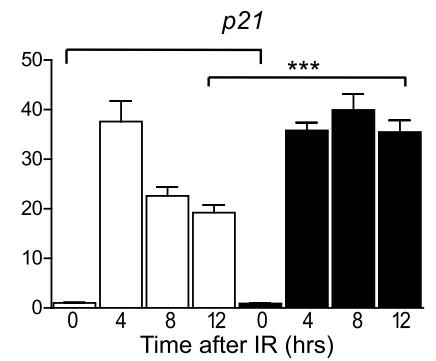

B

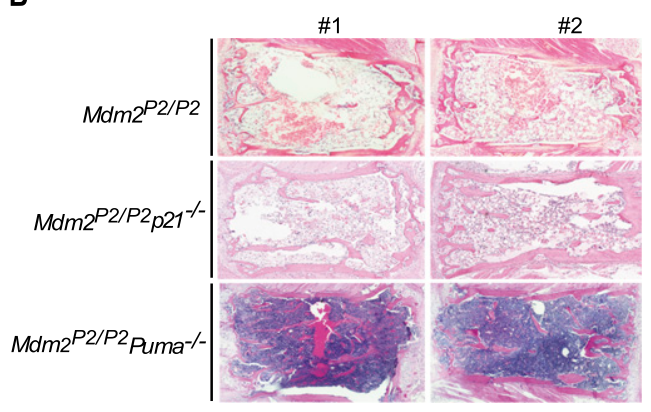

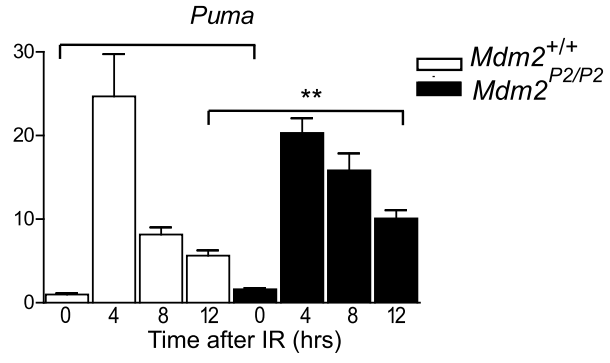

C

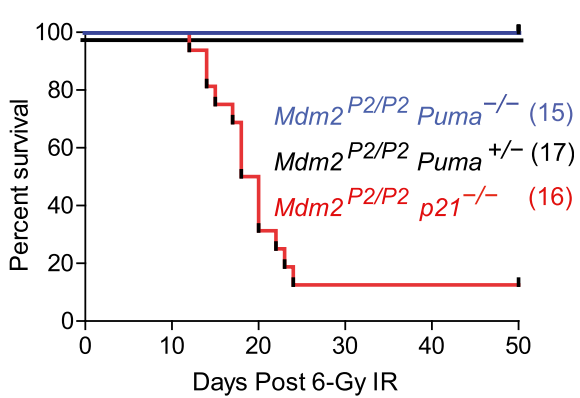

Figure 5. Absence of feedback loop promotes p53-dependent apoptosis in irradiated $M d m 2^{P 2 / P 2}$ mice. (A) Relative $p 21$ and Puma mRNA induction in $M d m 2^{+/+}$and $M d m 2^{P 2 / P 2} \mathrm{BM}$ cells at different time points normalized to Rplp0 mRNA levels with - IR sample set to $1 . n=6, \pm$ SEM; $P$-value was calculated by Student's $t$-test. $(B)$ Hematoxylin and eosin-stained BM sections of $M d m 2^{P 2 / P 2}$, $M d m 2^{P 2 / P 2} p 21^{-/-}$, and $M d m 2^{P 2 / P 2} P u m a^{-/-}$mice $12 \mathrm{~d}$ after 6 Gy IR (10× magnification). (C) Kaplan-Meier survival curve for 6 Gy irradiated $M d m 2^{P 2 / P 2} p 21^{-1-}$ and $M d m 2^{P 2 / P 2} P_{u m a^{-1-}}$ mice.

that $\mathrm{Mdm} 2$ monoubiquitinates p53 and primes it for subsequent polyubiquitination and degradation in collaboration with other proteins (Grossman et al. 2003; Li et al. 2003). It is also possible that some as yet unknown E3 ligase is involved in p53 degradation after DNA damage in a p53dependent fashion. Feedback-deficient $M d m 2^{P 2 / P 2}$ mice provide an excellent system to test these hypotheses in the future.

Regardless, the activity of p53 is compromised in $M d m 2^{P 2 / P 2}$ mice after DNA damage. While the absence of stress-induced $\mathrm{Mdm} 2$ does not significantly alter p53 protein levels, it does result in a modest increase in p53 activity that is well tolerated by most $M d m 2^{P 2 / P 2}$ mouse tissues. However, this increase in p53 activity turns catastrophic for the integrity of the hematopoietic system. Eighty percent of the $M d m 2^{P 2 / P 2}$ mice die due to hematopoietic failure, while all wild-type mice survive. The post-IR death of $M d m 2^{P 2 / P 2}$ mice could be simply averted by BM transplantation with wild-type donor cells. The hematopoietic system is in fact the most radiosensitive tissue and functions as a readout for small increases in p53 activity (Komarova et al. 2000; Liu et al. 2007; Terzian et al. 2007; Abbas et al. 2010; Wang et al. 2011). The importance of $\mathrm{Mdm} 2$ in inhibition of IR-induced p53 activity has been observed in heterozygous or hypomorphic Mdm2 mice (Mendrysa et al. 2003; Terzian et al. 2007). However, these mice have low levels of basal Mdm2 and correspondingly higher basal p53 activity, which is easily enhanced to lethal limits by IR. In contrast, $M d m 2^{P 2 / P 2}$ mice have normal levels of $\mathrm{Mdm} 2$ from the P1 promoter and normal p53 activity. Thus, the specific role of p53-induced Mdm2 could be clearly evaluated in these mice.

In the absence of the p53-Mdm2 feedback loop and in response to DNA damage, a modest increase in p53 activity promotes apoptosis of HSCs/CLPs/CMPs and impairs the normal dynamics of progenitor cell proliferation.
A

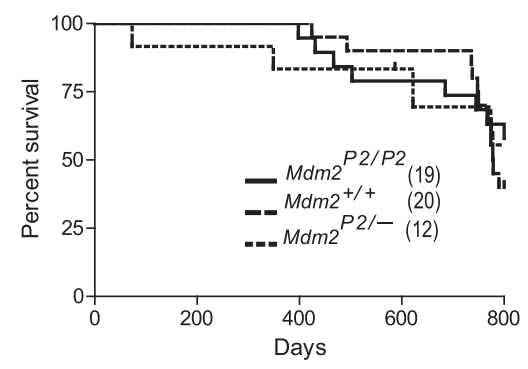

B

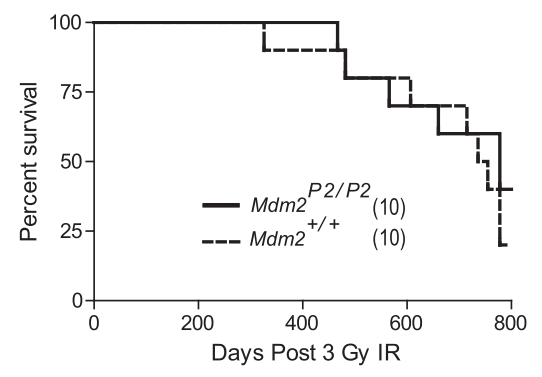

Figure 6. Lack of p53-Mdm2 feedback loop does not affect life span. (A) Kaplan-Meier survival curve for $M d m 2^{+/+}, M d m 2^{P 2 / P 2}$, and $M d m 2^{P 2 /-}$ mice. (B) Kaplan-Meier survival curve for $M d m 2^{+/+}$and $M d m 2^{P 2 / P 2}$ mice after 3 Gy IR. Curves are censored at $800 \mathrm{~d}$. 
Crosses with p53-null mice rescue the phenotype, suggesting p53 dependence. More importantly, crosses with Puma-null mice (an apoptotic gene that is a target of p53) but not $p 21$-null mice (cell cycle arrest/senescent target of p53) completely rescue the stem cell phenotype. Thus, it is the p53-mediated apoptosis pathway that causes the demise of the animals after DNA damage. To our knowledge, this is the first study to simultaneously evaluate the role of p53-dependent apoptotic and cell cycle arrest pathways in determining radiation sensitivity in a mouse model.

Previously, mathematical modeling predicted that the autoregulatory loop controls the frequency and amplitude of p53 DNA damage response (Lahav et al. 2004). Our data suggest that it also regulates the duration of the p53 response in vivo. In particular, this is emphasized in the hematopoietic compartment after DNA damage, wherein the basal Mdm2 levels are likely insufficient. It will be interesting to test whether other tissue stem cells are also similarly sensitized in the $M d m 2^{P 2 / P 2}$ mice.

We also show that absence of the feedback loop does not promote aging or impede stem cell function under normal or low-dose IR (3 Gy) conditions. This suggests that it is dispensable for normal homeostasis and protection against minor stress conditions. Moreover, Mdm2 levels expressed from the single P1 promoter are sufficient in sustaining normal life. Overall, these results challenge our conventional view of the p53-Mdm2 feedback loop and question the accepted role of $\mathrm{Mdm} 2$ as the sole E3 ubiquitin ligase for stress-induced p53. Furthermore, these results imply that while basal levels of $M d m 2$ (from the P1 promoter) are required for p53 degradation, the primary function of increased $M d m 2$ levels (from the P2 promoter) pertains to regulating p53 activity.

These results have clinical relevance, as activation of wild-type p53 is currently being evaluated for therapeutic purposes in the clinic. Our results here suggest that pharmacological inhibition of the p53-Mdm2 interaction in combination with DNA damage can be explored as a potential therapeutic strategy for p53 activation in the hematopoietic system. In particular, such strategies can be used for sensitizing stem cells in hematological malignancies. Indeed, similar approaches are currently being tested in the clinic for leukemia treatment (Cheok et al. 2011). These strategies provide a relatively safer alternative in lieu of the high-dose radio/chemotherapy regimens and associated side effects.

\section{Materials and methods}

\section{Targeting construct and generation of mice}

The Xho1-Xho1 DNA fragment $(1 \mathrm{~kb})$ from intron 2 of mouse $M d m 2$ covering the $\mathrm{P} 2$ promoter and the $\mathrm{p} 53$ response elements was cloned into pBluescript vector. Site-directed mutagenesis was carried out using QuickChange kit (Stratagene). An EcoRV restriction enzyme site was created at the second p53 response element to enable us to distinguish wild-type and mutant alleles for genotyping. Mutated DNA was sequenced and cloned as part of the $5-\mathrm{kb} 5^{\prime}$ homologous arm into $p L G 1$ targeting vector backbone. A 1.2-kb homologous fragment was added as the
3' arm. Lox-pGKNeo-Lox and Hsv-Tk1 cassettes were included for positive and negative selection, respectively (Fig. 1A). The targeting construct was sequenced completely and electroporated into TC1 mouse ES cells. G418-resistant clones were analyzed for correct homologous recombination by Southern blotting using $5^{\prime}$ and $3^{\prime}$ external probes (Fig. 1A). Two independent correctly targeted clones were expanded and injected into $\mathrm{C} 57 \mathrm{BL} / 6$ blastocysts to generate $\mathrm{Mdm} 2^{P 2 /+}$ chimeras. Male chimeras were backcrossed to C57BL/6 mice to secure germline transmission of the mutant allele.

\section{Mouse breeding, maintenance, and genotyping}

p53-null and CD45.1 mice were purchased from Jackson Laboratories. $p 21$-null mice were a gift from Dr. T. Jacks (Massachusetts Institute of Technology), and Puma-null mice were from Dr. G. Zambetti (St. Jude Children's Research Hospital). $M d m 2^{+/-}$ and $M d m 4^{\Delta 2 /+}$ mice have been described previously (Montes de Oca Luna et al. 1995; Xiong et al. 2006). Mice were maintained in $>90 \%$ C57BL/6 background. All mouse studies were conducted in compliance with Institutional Animal Care and Use Committee protocols. Genotyping was carried out either as described earlier (Post et al. 2010) or by PCR amplification over the p53 response elements with primer sets Mdm2-F (5'-GGTCCAGG AGGTGACAGGT-3') and Mdm2-R (5'-ACGTCTTTCGGCAA TAGCTC-3') followed by EcoRV digestion and resolution on agarose gel.

\section{Protein analysis}

Protein lysates were prepared by lysing tissues or MEFs in NP-40 buffer. Protein estimation was carried out with BCA (Protein Assay kit, Pierce). Fifty micrograms of lysate was resolved on $8 \%$ SDS-PAGE and immunoblotted with antibodies against $\mathrm{Mdm} 2$ (1:500; 2A10, Calbiochem), Mdm4 (1:500; MX82, Sigma), p53 (1:1000; CM5, Vector Laboratories), S18-p53 (1:1000; 9284, Cell Signaling), Vinculin (1:1000; V9131, Sigma), and p21 (1:1000; 556431, BD Pharmingen). Western blots were repeated at least three times with biological replicates. p53 expression was quantitated using ImageJ software (National Institutes of Health [NIH]).

\section{ChIP assay}

Spleens harvested from irradiated and nonirradiated mice were washed with PBS and frozen-pulverized under liquid nitrogen. Chromatin was fixed with formaldehyde, and ChIP assay was carried out as described earlier (Jackson and Pereira-Smith 2006).

\section{Quantitative RT-PCR}

RNA isolation and quantitative RT-PCR were carried out as previously described in Pant et al. (2011).

\section{MEF preparation and cell culture}

MEFs prepared from 13.5 d post-coitum (dpc) embryos were maintained in Dulbecco's modified Eagle's medium (DMEM) (Invitrogen) supplemented with 10\% FBS and penicillin (100 IU/ $\mathrm{mL}) /$ streptomycin $(100 \mu \mathrm{g} / \mathrm{mL})$. Early passage MEFs (P2-P3) were used for analysis.

\section{IR and UV studies}

Mice were irradiated at 6 Gy in a cesium-137 irradiator and killed at different time points. Tissues were harvested and lysed in NP-40 buffer for protein or TRIzol for RNA analyses. MEFs cultured in a $100-\mathrm{mm}$ tissue culture dish were irradiated at 
10 Gy. For UV studies, MEFs were exposed to $50 \mathrm{~J} / \mathrm{m}^{2} \mathrm{UV}$ in a Stratalinker (Stratagene) without the medium. Fresh medium was added, and cells were incubated at $37^{\circ} \mathrm{C}$ before harvesting at different time points for experimental analyses.

\section{$B M$ harvesting and flow cytometry}

$\mathrm{BM}$ cells were harvested from femurs and tibias of $M d m 2^{P 2 / P 2}$ and $M d \mathrm{~m}^{+/+}$mice in PBS. Cell suspension was passed through an 18.5-gauge needle and finally filtered through a $40-\mu \mathrm{m}$ filter. All cellular suspensions were kept on ice until further processing. For flow cytometry, murine HSCs and CLPs/CMPs were identified using (eBioscience) fluorochrome-conjugated antibodies against ckit (PEcyanine7) and Sca-1 (allophycocyanin) and for lineage depletion, we used CD4 (phycoerythrin [PE]), CD8a (PE), B220 (PE), Ter119 (PE), Mac-1 (PE), and Gr-1 (PE) in $\mathrm{HBSS}^{+}$. Cells were stained for $20 \mathrm{~min}$ in the dark on ice and then washed with $\mathrm{HBSS}^{+}$. We analyzed 1.25 million cells on BD LSRII System at the University of Texas M.D. Anderson Cancer Center Flow Cytometry Core Facility. Dead cells were excluded with DAPI staining (eBioscience).

\section{BM transplantation}

Donor BM cells were isolated from wild-type (CD45.1) or $M d m 2^{P 2 / P 2}(\mathrm{CD} 45.2)$ mice. For a noncompetitive assay, $2.5 \times 10^{5}$ cells from the donor mouse were tail vein-injected into lethally irradiated recipient mice. For a competitive transplantation assay, either $2.5 \times 10^{5}$ cells each from unirradiated wild-type (CD45.1) and unirradiated $M d m 2^{P 2 / P 2}$ (CD45.2) mice were mixed or $2.5 \times 10^{5}$ cells from unirradiated wild-type mouse (CD45.1) were mixed with $1 \times 10^{6}$ cells from irradiated $M d m 2^{P 2 / P 2}$ (CD45.2) mice and tail vein-injected into lethally irradiated recipient wild-type (CD45.1) mice. Eight weeks and 16 wk after transplants, retro-orbitally drawn peripheral blood was stained with leukocyte marker antibodies and analyzed by flow cytometry for donor reconstitution.

\section{Apoptosis and cell cycle analyses}

Thymocytes derived from thymi and BM cells harvested from femurs and tibias of irradiated/unirradiated mice were analyzed for apoptosis by Annexin-V FITC flow cytometry (Apolert Annexin-V FITC apoptosis kit, Clontech) per the manufacturer's instructions. For cell cycle, $10 \mathrm{~Gy}$ irradiated MEFs were incubated for $23 \mathrm{~h}$ at $37^{\circ} \mathrm{C}$ and processed as per the manufacturer's instructions (Click-iT EdU Alexa Fluor 488 flow cytometry assay kit, Invitrogen) for analysis on BD FACS Calibur System.

\section{Histopathology and immunohistochemistry}

Tissues harvested from $M d m 2^{P 2 / P 2}$ and $M d m 2^{+/+}$mice were fixed in $10 \%$ buffered formalin saline and paraffin-embedded. Fivemicrometer sections were stained by hematoxylin and eosin and examined by light microscopy. Selected unstained sections were immunohistochemically analyzed with respective antibodies.

\section{Statistical analysis}

$P$-value was calculated by Student's $t$-test using Graphpad software, and values $<0.05$ were considered significant. $\left(^{\star}\right) P<0.05$, $\left(^{\star \star}\right) P<0.01$, and $\left(^{\star \star \star}\right) P<0.001$.

\section{Acknowledgments}

Mice were made by the GEM Facility at M.D. Anderson Cancer Center. Studies were supported by Cancer Center support grant CA016672 and NIH grant CA47296 to G.L. V.P. was supported in part by a NIH training grant in Molecular Genetics of Cancer (CA009299) and the Brown Foundation. V.P. designed and performed most of the experiments and wrote the manuscript. S.X. performed thymocyte culture and apoptosis assays. J.G.J. performed ChIP assays. S.M.P. provided the vector for targeting and helped in BM isolation. H.A.A. performed LSK flow cytometry analysis. A.Q.C. performed BM differential counts and microscopy. A.N.H. is the pathologist associated with the study. V.P. and G.L conceived the project. G.L. guided the overall research work.

\section{References}

Abbas HA, Maccio DR, Coskun S, Jackson JG, Hazen AL, Sills TM, You MJ, Hirschi KK, Lozano G. 2010. Mdm2 is required for survival of hematopoietic stem cells/progenitors via dampening of ROS-induced p53 activity. Cell Stem Cell 7: 606-617.

Barak Y, Juven T, Haffner R, Oren M. 1993. mdm2 expression is induced by wild type p53 activity. EMBO J 12: 461-468.

Barak Y, Gottlieb E, Juven-Gershon T, Oren M. 1994. Regulation of $\mathrm{mdm} 2$ expression by $\mathrm{p} 53$ : Alternative promoters produce transcripts with nonidentical translation potential. Genes Dev 8: 1739-1749.

Cheng T, Rodrigues N, Shen H, Yang Y, Dombkowski D, Sykes M, Scadden DT. 2000. Hematopoietic stem cell quiescence maintained by p21cip1/waf1. Science 287: 1804-1808.

Cheok CF, Verma CS, Baselga J, Lane DP. 2011. Translating p53 into the clinic. Nat Rev Clin Oncol 8: 25-37.

Christophorou MA, Ringshausen I, Finch AJ, Swigart LB, Evan GI. 2006. The pathological response to DNA damage does not contribute to p53-mediated tumour suppression. Nature 443: 214-217.

Francoz S, Froment P, Bogaerts S, De Clercq S, Maetens $M$, Doumont G, Bellefroid E, Marine JC. 2006. Mdm4 and Mdm2 cooperate to inhibit p53 activity in proliferating and quiescent cells in vivo. Proc Natl Acad Sci 103: 3232-3237.

Gannon HS, Woda BA, Jones SN. 2012. ATM phosphorylation of Mdm2 Ser394 regulates the amplitude and duration of the DNA damage response in mice. Cancer Cell 21: 668-679.

Grossman SR, Deato ME, Brignone C, Chan HM, Kung AL, Tagami H, Nakatani Y, Livingston DM. 2003. Polyubiquitination of $\mathrm{p} 53$ by a ubiquitin ligase activity of $\mathrm{p} 300$. Science 300: 342-344.

Haupt Y, Maya R, Kazaz A, Oren M. 1997. Mdm2 promotes the rapid degradation of p53. Nature 387: 296-299.

Honda R, Tanaka H, Yasuda H. 1997. Oncoprotein MDM2 is a ubiquitin ligase E3 for tumor suppressor p53. FEBS Lett 420: $25-27$.

Itahana $\mathrm{K}$, Mao $\mathrm{H}$, Jin A, Itahana $\mathrm{Y}$, Clegg HV, Lindstrom MS, Bhat KP, Godfrey VL, Evan GI, Zhang Y. 2007. Targeted inactivation of Mdm2 RING finger E3 ubiquitin ligase activity in the mouse reveals mechanistic insights into p53 regulation. Cancer Cell 12: 355-366.

Jackson JG, Pereira-Smith OM. 2006. Primary and compensatory roles for RB family members at cell cycle gene promoters that are deacetylated and downregulated in doxorubicininduced senescence of breast cancer cells. Mol Cell Biol 26: 2501-2510.

Jones SN, Roe AE, Donehower LA, Bradley A. 1995. Rescue of embryonic lethality in Mdm2-deficient mice by absence of p53. Nature 378: 206-208.

Komarova EA, Christov K, Faerman AI, Gudkov AV. 2000. Different impact of $\mathrm{p} 53$ and $\mathrm{p} 21$ on the radiation response of mouse tissues. Oncogene 19: 3791-3798.

Komarova EA, Kondratov RV, Wang K, Christov K, Golovkina TV, Goldblum JR, Gudkov AV. 2004. Dual effect of p53 on 
radiation sensitivity in vivo: p53 promotes hematopoietic injury, but protects from gastro-intestinal syndrome in mice. Oncogene 23: 3265-3271.

Kubbutat MH, Jones SN, Vousden KH. 1997. Regulation of p53 stability by Mdm2. Nature 387: 299-303.

Lahav G, Rosenfeld N, Sigal A, Geva-Zatorsky N, Levine AJ, Elowitz MB, Alon U. 2004. Dynamics of the p53-Mdm2 feedback loop in individual cells. Nat Genet 36: 147-150.

Lane DP. 1992. Cancer. p53, guardian of the genome. Nature 358: $15-16$.

Lewandoski M, Wassarman KM, Martin GR. 1997. Zp3-cre, a transgenic mouse line for the activation or inactivation of loxP-flanked target genes specifically in the female germ line. Curr Biol 7: 148-151.

Li M, Brooks CL, Wu-Baer F, Chen D, Baer R, Gu W. 2003. Mono- versus polyubiquitination: Differential control of p53 fate by Mdm2. Science 302: 1972-1975.

Liu G, Parant JM, Lang G, Chau P, Chavez-Reyes A, El-Naggar AK, Multani A, Chang S, Lozano G. 2004. Chromosome stability, in the absence of apoptosis, is critical for suppression of tumorigenesis in Trp53 mutant mice. Nat Genet 36: 63-68.

Liu G, Terzian T, Xiong S, Van Pelt CS, Audiffred A, Box NF, Lozano G. 2007. The p53-Mdm2 network in progenitor cell expansion during mouse postnatal development. I Pathol 213: 360-368.

Liu Y, Elf SE, Miyata Y, Sashida G, Huang G, Di Giandomenico S, Lee JM, Deblasio A, Menendez S, Antipin J, et al. 2009. p53 regulates hematopoietic stem cell quiescence. Cell Stem Cell 4: 37-48.

Liu D, Ou L, Clemenson GD Jr, Chao C, Lutske ME, Zambetti GP, Gage FH, Xu Y. 2010. Puma is required for p53-induced depletion of adult stem cells. Nat Cell Biol 12: 993-998.

Marine JC, Francoz S, Maetens M, Wahl G, Toledo F, Lozano G. 2006. Keeping p53 in check: Essential and synergistic functions of Mdm2 and Mdm4. Cell Death Differ 13: 927-934.

Mendrysa SM, Perry ME. 2000. The p53 tumor suppressor protein does not regulate expression of its own inhibitor, MDM2, except under conditions of stress. Mol Cell Biol 20: 20232030.

Mendrysa SM, McElwee MK, Michalowski J, O'Leary KA, Young KM, Perry ME. 2003. mdm2 Is critical for inhibition of p53 during lymphopoiesis and the response to ionizing irradiation. Mol Cell Biol 23: 462-472.

Mendrysa SM, O'Leary KA, McElwee MK, Michalowski J, Eisenman RN, Powell DA, Perry ME. 2006. Tumor suppression and normal aging in mice with constitutively high p53 activity. Genes Dev 20: 16-21.

Momand J, Zambetti GP, Olson DC, George D, Levine AJ. 1992. The $\mathrm{mdm}-2$ oncogene product forms a complex with the p53 protein and inhibits p53-mediated transactivation. Cell 69: 1237-1245.

Montes de Oca Luna R, Wagner DS, Lozano G. 1995. Rescue of early embryonic lethality in mdm2-deficient mice by deletion of p53. Nature 378: 203-206.

Oliner JD, Pietenpol JA, Thiagalingam S, Gyuris J, Kinzler KW, Vogelstein B. 1993. Oncoprotein MDM2 conceals the activation domain of tumour suppressor p53. Nature 362: 857860.

Pant V, Xiong S, Iwakuma T, Quintas-Cardama A, Lozano G. 2011. Heterodimerization of Mdm2 and Mdm4 is critical for regulating p53 activity during embryogenesis but dispensable for p53 and Mdm2 stability. Proc Natl Acad Sci 108: 11995-12000.

Post SM, Quintas-Cardama A, Pant V, Iwakuma T, Hamir A, Jackson JG, Maccio DR, Bond GL, Johnson DG, Levine AJ, et al. 2010. A high-frequency regulatory polymorphism in the p53 pathway accelerates tumor development. Cancer Cell 18: 220-230.

Ringshausen I, O'Shea CC, Finch AJ, Swigart LB, Evan GI. 2006. $\mathrm{Mdm} 2$ is critically and continuously required to suppress lethal p53 activity in vivo. Cancer Cell 10: 501-514.

Saucedo LJ, Carstens BP, Seavey SE, Albee LD 2nd, Perry ME. 1998. Regulation of transcriptional activation of $\mathrm{mdm} 2$ gene by p53 in response to UV radiation. Cell Growth Differ 9: 119-130.

Shao L, Sun Y, Zhang Z, Feng W, Gao Y, Cai Z, Wang ZZ, Look AT, Wu WS. 2010. Deletion of proapoptotic Puma selectively protects hematopoietic stem and progenitor cells against high-dose radiation. Blood 115: 4707-4714.

Terzian T, Wang Y, Van Pelt CS, Box NF, Travis EL, Lozano G. 2007. Haploinsufficiency of Mdm2 and Mdm4 in tumorigenesis and development. Mol Cell Biol 27: 5479-5485.

Terzian T, Suh YA, Iwakuma T, Post SM, Neumann M, Lang GA, Van Pelt CS, Lozano G. 2008. The inherent instability of mutant p53 is alleviated by Mdm2 or p16INK4a loss. Genes Dev 22: 1337-1344.

Tyner SD, Venkatachalam S, Choi J, Jones S, Ghebranious N, Igelmann H, Lu X, Soron G, Cooper B, Brayton C, et al. 2002. p53 mutant mice that display early ageing-associated phenotypes. Nature 415: 45-53.

van Os R, Kamminga LM, Ausema A, Bystrykh LV, Draijer DP, van Pelt K, Dontje B, de Haan G. 2007. A Limited role for p21Cip1/Waf1 in maintaining normal hematopoietic stem cell functioning. Stem Cells 25: 836-843.

Vousden KH, Lu X. 2002. Live or let die: The cell's response to p53. Nat Rev Cancer 2: 594-604.

Wang YV, Leblanc M, Fox N, Mao JH, Tinkum KL, Krummel K, Engle D, Piwnica-Worms D, Piwnica-Worms H, Balmain A, et al. 2011. Fine-tuning p53 activity through C-terminal modification significantly contributes to HSC homeostasis and mouse radiosensitivity. Genes Dev 25: 1426-1438.

Wu X, Bayle JH, Olson D, Levine AJ. 1993. The p53-mdm-2 autoregulatory feedback loop. Genes Dev 7: 1126-1132.

Xiong S, Van Pelt CS, Elizondo-Fraire AC, Liu G, Lozano G. 2006. Synergistic roles of $\mathrm{Mdm} 2$ and $\mathrm{Mdm} 4$ for p53 inhibition in central nervous system development. Proc Natl Acad Sci 103: 3226-3231.

Yu H, Shen H, Yuan Y. XuFeng R, Hu X, Garrison SP, Zhang L, Yu J, Zambetti GP, Cheng T. 2010. Deletion of Puma protects hematopoietic stem cells and confers long-term survival in response to high-dose $\gamma$-irradiation. Blood 115: 3472-3480.

Zauberman A, Flusberg D, Haupt Y, Barak Y, Oren M. 1995. A functional p53-responsive intronic promoter is contained within the human mdm2 gene. Nucleic Acids Res 23: 2584-2592. 